\title{
PERBANDINGAN ANTARA PEMBERIAN PROGESTERON VAGINAL DAN ALLYLESTRENOL ORAL PADA PENANGANAN ABORTUS IMINENS
}

\author{
Umar Dhani ${ }^{1}$, Ova Emilia², Risanto Siswosudarmo³
}

\begin{abstract}
Background: Abortion is still the most common complication of pregnancy. Inadequate secretion of progesterone in early pregnancy has been associated with one of the cause of miscarriage. Progesterone supplementation has been used to prevent abortion but it is still debatable.

Objective: To compare the success rate of vaginal progesterone vs oral allylestrenol in the treatment of threatened abortion and duration of maintaining pregnancy.
\end{abstract}

Method: Randomized Clinical Trial. The study was conducted at four affiliated hospitals of Sardjito hospital Yogyakarta from November 2013 to May 2014. Subjects with the diagnosis threatened abortion meeting the following criteria were included: 8-16 weeks gestational age, hemoglobin content eH $10 \mathrm{~g} / \mathrm{dL}$, and live fetus. The following patients were excluded: there was a history of induced abortion, hormonal treatment, associated with IUD use, uterine anomaly and gynecology tumor. A total of 60 patients were recruited to obtain 0.6 times proportion difference and $80 \%$ power of study. Eligible subjects consisting of 30 and 29 were randomly allocated into vaginal progesterone and oral allylestrenol groups. Ability to maintain, duration of pregnancy and side effects were outcomes of interest. Chi-square, t-test, Fisher exact test and survival analysis were used for statistical analysis. Result \& Discussion: Abortion rate in vaginal progesterone was $23.3 \%$ compared $37.9 \%$ with oral allylestrenol group ( $R R=0.61 ; 95 \% \mathrm{Cl} 0.27-1.36)$. Duration of maintaining pregnancy was 16.57 days vs 9.82 days in vaginal progesterone and oral allylestrenol respectively (mean difference 6.75 days; $95 \% \mathrm{Cl} 2.30-11.20$ ). There was no difference in term of gestational age on the abortion rate $(p>0.05)$. One case undergoing nausea was found in oral allylestrenol group.

Conclusion: There was no difference between vaginal progesterone and oral allylestrenol in term of abortion rate. Vaginal progesterone could maintain pregnancy longer than oral allylestrenol.

Keywords: Threatened abortion, Vaginal progesterone, Oral allylestrenol, Abortion rate, Side effect.

\begin{abstract}
ABSTRAK
Latar Belakang: Abortus masih merupakan komplikasi kehamilan yang sering terjadi. Sekresi progesteron yang tidak memadai pada awal kehamilan telah dikaitkan dengan salah satu penyebab abortus. Suplementasi progesteron digunakan untuk mencegah keguguran spontan walaupun masih diperdebatkan.

Tujuan: Membandingkan keberhasilan terapi progesteron vaginal vs. allylestrenol oral dalam hal kejadian abortus dan lama terjadinya abortus pada kasus abortus iminens.

Metode: Randomized Clinical Trial. Penelitian dilakukan dibagian Obstetrika dan Ginekologi di RS Kabupaten yang merupakan afiliasi RS Sardjito dari bulan November 2013 sampai dengan Mei 2014. Subyek yang memenuhi kriteria berikut ini: hamil 8-16 minggu, terdiagnosis abortus iminens, kadar hemoglobin $>10 \mathrm{~g} / \mathrm{dL}$, dan janin hidup. Pasien berikut ini tidak dimasukkan dalam penelitian: riwayat abortus provokatus, riwayat penggunaan terapi hormonal, abortus imminens karena kegagalan IUD, anomali uterus dan tumor ginekologis. Sebanyak 60 pasien diikutsertakan dalam penelitian ini untuk mendapatkan beda proporsi kejadian abortus sebesar 0,6 kali
\end{abstract}

\footnotetext{
$\overline{1,2,3}$ Bagian Obstetrik dan Ginekologi Fakultas Kedokteran Universitas Gadjah Mada/RS SardjitoYogyakarta
} 
dengan kekuatan penelitian sebesar $80 \%$. Subjek dibagi menjadi dua kelompok secara random yaitu kelompok yang mendapat progesteron vaginal dan allylestrenol oral masing-masing sebanyak 30 dan 29 . Keberhasilan mempertahankan kehamilan, lama hari bertahan dan efek samping adalah hasil yang dinilai. Uji Chi-square, $t$ test, uji Fisher dan analisis survival adalah uji statistik yang dipakai.

Hasil \& Pembahasan: Kejadian abortus pada kelompok progesteron vaginal adalah 23,3\% dibanding, 37,9\% pada kelompok allylestrenol oral ( $\mathrm{RR}=0,61 ; 95 \% \mathrm{Cl} 0,27-1,36)$. Lama bertahan pada kelompok progesteron vaginal ratarata 16,57 hari dibanding rata-rata 9,82 hari pada kelompok allylestrenol oral (beda rata-rata 6,75 hari; $95 \% \mathrm{Cl}$ 2,30-11,20). Tidak ada perbedaan bermakna pengaruh umur kehamilan terhadap kejadian abortus pada kedua kelompok $(p>0,05)$. Efek samping berupa perasaan mual hanya dijumpai pada kelompok allylestrenol oral.

Kesimpulan: Tidak terdapat perbedaan kejadian abortus pada kedua kelompok meskipun kemampuan bertahan lebih lama pada kelompok progesteron vaginal.

Kata Kunci: Abortus iminens, progesteron vaginal, allylestrenol oral, angka abortus, efek samping.

\section{PENDAHULUAN}

Abortus adalah keluarnya produk kehamilan sebelum usia kehamilan 23 minggu berdasarkan hari pertama haid terakhir. ${ }^{1}$ Abortus terjadi sekitar $15 \%$ jumlah kehamilan dan merupakan komplikasi kehamilan yang sering terjadi. Sekitar $50-60 \%$ abortus dapat disebabkan oleh karena adanya kelainan kromosom janin, infeksi, kelainan endokrin, dan kelainan anatomi uterus, dan sekitar $40-50 \%$ belum bisa dijelaskan. ${ }^{2}$ Abortus iminens ditandai oleh perdarahan vaginal pada kehamilan trimester pertama, dengan atau tanpa nyeri perut dan serviks masih tertutup serta janin masih viabel dan berada di dalam uterus. Ketika serviks mulai berdilatasi, abortus atau kegagalan kehamilan tidak akan terelakkan. $^{3}$

Progesteron disekresi selama awal kehamilan oleh korpus luteum di ovarium. Progesteron merupakan hormon yang penting untuk pembentukan dan pemeliharaan kehamilan dengan menginduksi perubahan sekret pada lapisan rahim, penting untuk implantasi sel telur yang telah dibuahi. Sekresi progesteron yang tidak memadai pada awal kehamilan merupakan salah satu penyebab abortus. Suplementasi progesteron telah digunakan sebagai pengobatan pada abortus iminens dan akan mencegah keguguran spontan. ${ }^{3}$ Banyak kasus kehamilan dengan abortus iminens yang dapat dipertahankan telah dilaporkan dengan hasil yang berbeda-beda. Beberapa penulis melaporkan angka keberhasilan mempertahankan kehamilan sebesar $80 \%$ dengan pemberian allylestrenol oral dan $88 \%$ dengan menggunakan progesteron vaginal. ${ }^{4,5}$

Berdasarkan hasil yang telah dilaporkan tersebut di atas banyak hal yang menarik untuk diteliti lebih lanjut terhadap keefektifan progesteron baik vaginal maupun oral dalam manajemen abortus iminens. Tujuan penelitian ini adalah membandingkan keberhasilan pemberian progesteron vaginal dengan allylestrenol oral dalam hal angka kejadian abortus dan lama (hari) mempertahankan kehamilan serta efek samping yang mungkin terjadi.

\section{METODE}

Bentuk rancangan adalah randomized clinical trial. Penelitian ini dilakukan di 5 rumah sakit jejaring pendidikan RS Sardjito Yogyakarta yaitu, RS Bantul, RS Wates, RS Wonosari, RS Muntilan dan RS Banjarnegara, dari November 2013 sampai Mei 2014. Kriteria inklusi dalam penelitian ini adalah pasien yang memenuhi kriteria berikut: hamil 8-16 minggu, terdiagnosis abortus iminens, kadar hemoglobin $\mathrm{e}^{\prime \prime}$ $10 \mathrm{~g} / \mathrm{dL}$, janin hidup dan bersedia mengikuti penelitian. Pasien dengan kriteria berikut ini tidak dimasukkan dalam penelitian: riwayat abortus provokatus, riwayat penggunaan terapi hormonal, 
abortus iminens karena kegagalan IUD, anomali uterus dan tumor ginekologis. Sebanyak 60 pasien diikutsertakan dalam penelitian ini untuk mendapatkan beda proporsi kejadian abortus sebesar 0,6 kali dengan kekuatan penelitian sebesar $80 \%$. Subjek dibagi menjadi dua kelompok secara random dengan menggunakan tabel bilangan random yang diperoleh dari komputer. Alokasi random menggunakan amplop tidak tembus cahaya. Penelitian ini tidak menggunakan blinding karena peneliti dan pasien mengetahui jenis obat yang diberikan. Sebanyak 59 pasien terdiri atas kelompok perlakuan (yang mendapat progesteron vaginal) sebanyak 30 orang dan kelompok kontrol (yang mendapat allylestrenol oral) sebanyak 29 orang. Keberhasilan mempertahankan kehamilan, lama hari bertahan dan efek samping adalah hasil yang dinilai. Uji Chi-square, $t$-test, uji Fisher dan analisis survival adalah uji statistik yang dipakai. Variabel tergantung pada penelitian ini adalah kejadian abortus, lama kejadian mempertahankan kehamilan dan efek samping. Variabel bebas adalah pemberian progesteron vaginal dan allylestrenol oral. Variabel luar adalah usia ibu, paritas dan indeks massa tubuh.

\section{HASIL DAN PEMBAHASAN}

Kejadian abortus baik pada kelompok perlakuan dan kelompok kontrol terlihat pada tabel berikut ini.

Tabel 1. Perbandingan pengaruh perlakuan terhadap kejadian abortus

\begin{tabular}{lcccccc}
\hline \multicolumn{1}{c}{ Perlakuan } & \multicolumn{2}{c}{$\begin{array}{c}\text { Abortus } \\
\text { Tidak }\end{array}$} & $\begin{array}{c}\text { Persen } \\
\text { Abortus }\end{array}$ & RR & Cl 95\% & $P$ \\
\hline Progesteron vaginal & 7 & 23 & 23,3 & 0,61 & $0,27-1,36$ & 0,22 \\
Allylestrenol oral & 11 & 18 & 37,9 & 1 & & \\
\hline
\end{tabular}

Hasil penelitian yang dilakukan menunjukkan bahwa dari 30 kasus yang mendapat terapi progesteron vaginal 7 pasien mengalami abortus, memberikan angka abortus 23,3\%. Pada kelompok allylestrenol oral didapat 11 dari 29 kasus yang mengalami abortus, atau 37,9\%. Meskipun secara statistik perbedaan ini tidak bermakna, tetapi secara klinis dengan angka risiko relatif sebesar 0,61 dapat dikatakan cukup bermakna karena pemberian progesteron vaginal dapat mengurangi risiko abortus sebanyak 0,39\%. Angka ini tidak jauh berbeda pada penelitian sebelumnya yang membandingkan pemberian allylestrenol oral dengan papaverin untuk terapi abortus iminens. ${ }^{4}$ Dalam cochrane review penggunaan progestogen vaginal dalam pengobatan abortus iminens memberikan risiko angka abortus 0,47 kali dibanding dengan plasebo. ${ }^{3}$ Meskipun secara statistik penelitian ini juga tidak bermakna tetapi dengan risiko relatif 0,47 kali maka hal ini menunjukkan bahwa progesteron vaginal dapat mempertahankan kehamilan hampir 2 kali lebih dibanding tanpa pemberian pengobatan.

Jika pada penelitian Sugito dan Siswosudarmo ${ }^{4}$ penilaian lama mempertahankan kehamilan sampai 22 minggu maka dalam penelitian ini keberhasilan mempertahankan kehamilan dinilai sampai umur kehamilan 23 minggu sesuai kriteria WHO. Pengaruh perlakuan terhadap lama mempertahankan kehamilan secara rata-rata dapat dilihat pada tabel berikut ini (Tabel 2). 
Umar Dhani et al., Perbandingan antara Pemberian Progesteron Vaginal dan Allylestrenol Oral pada Penanganan Abortus Iminens

Tabel 2. Lama terjadinya abortus setelah diagnosis pada kedua kelompok (hari).

\begin{tabular}{lcccc}
\hline Perlakuan & $\begin{array}{c}\text { Rata-rata } \\
\text { lama bertahan }\end{array}$ & Beda rerata & Cl 95\% & $\rho$ \\
\hline Progesteron vaginal & $16,57 \pm 5,41$ & 6,75 & $2,30-11,20$ & 0,005 \\
Allylestrenol oral & $9,82 \pm 3,54$ & & & \\
\hline
\end{tabular}

Bila dilihat dari jarak waktu lama mempertahankan kehamilan penelitian ini menunjukkan bahwa lama mempertahankan kehamilan sejak diagnosis sampai terjadi abortus rata-rata adalah 12,44 hari. Pada kelompok progesteron vaginal lama mempertahankan kehamilan adalah 16,57 hari sedang pada kelompok allylestrenol oral rata-rata 9,82 hari. Meskipun secara statistik perbedaan tersebut bermakna tetapi secara klinis tidak karena dengan perbedaan kurang lebih 7 hari tidak mempunyai arti klinis yang penting karena kedua-duanya berakhir dengan abortus. Hal ini juga terjadi pada penelitian Sugito dan Siswosudarmo ${ }^{4}$ mengenai lama terjadinya abortus pada allylestrenoloral dalam mempertahankan kehamilan yaitu 15,6 hari.

Kejadian abortus ternyata juga dipengaruhi oleh umur kehamilan saat gejala abortus terlihat pertama kali. Tabel berikut menunjukkan pengaruh umur kehamilan terhadap kejadian abortus (Tabel 3).

Tabel 3. Pengaruh umur kehamilan saat diagnosis terhadap kejadian abortus (semua kasus).

\begin{tabular}{ccccccc}
\hline $\begin{array}{c}\text { Umur kehamilan } \\
\text { (minggu) }\end{array}$ & \multicolumn{2}{c}{ Abortus } & $\begin{array}{c}\text { Persen } \\
\text { Abortus }\end{array}$ & RR & Cl 95\% & $P$ \\
\hline 10 & 6 & 27 & 18,2 & 0,39 & $0,17-0,91$ & 0,02 \\
$<10$ & 12 & 14 & 46,2 & 1 & & \\
\hline
\end{tabular}

Tabel tersebut menunjukkan bahwa kejadian abortus pada kelompok kehamilan $<10$ minggu hampir tiga kali lebih besar daripada yang kehamilan $>10$ minggu, secara statistik perbedaan ini bermakna $(p<0,05)$. Hasil ini sesuai dengan penelitian lain yang mendapatkan bahwa jika umur kehamilan kurang dari 10 minggu kejadian abortus adalah tiga kali lebih besar dibanding umur kehamilan lebih dari 10 minggu. ${ }^{6}$
Jika antara kelompok progesteron vaginal dengan kelompok allylestrenol oral dipisahkan, maka kejadian abortus pada kelompok progesteron vaginal dilihat dari saat diagnosis untuk kehamilan e" 10 minggu dibanding < 10 minggu tidak didapati perbedaan yang bermakna (Tabel 4). 
Tabel 4. Pengaruh umur kehamilan saat diagnosis terhadap kejadian abortus (kelompok progesteron vaginal dan allylestrenol oral).

\begin{tabular}{ccccccc}
\hline $\begin{array}{c}\text { Umur kehamilan } \\
\text { (minggu) }\end{array}$ & \multicolumn{2}{c}{ Abortus } & $\begin{array}{c}\text { Persen } \\
\text { Abortus }\end{array}$ & RR & Cl 95\% & $P$ \\
\hline $\begin{array}{c}\text { Progesteron } \\
\geq 10\end{array}$ & 2 & 15 & 11,8 & 0,30 & $0,07-1,33$ & 0,08 \\
$<10$ & 5 & 8 & 38,5 & 1 & & \\
$\begin{array}{c}\text { Allylesrenol } \\
\geq 10\end{array}$ & 4 & 12 & 25 & 0,46 & $0,17-1,24$ & 0,11 \\
$<10$ & 7 & 6 & 53,8 & 1 & & \\
\hline
\end{tabular}

Berdasarkan studi literatur, progesteron diproduksi oleh corpus luteum sampai usia 10 minggu. ${ }^{7,8}$ Setelah masa transisi (antara minggu 7 dan 11), plasenta mengambil alih peran korpus luteum dalam menghasilkan progesteron. Dengan makin tuanya kehamilan berarti makin baik produksi hormon plasenta sehingga respon terhadap pengobatan hormonal lebih baik. Pemberian progesteron vaginal pada kasus abortus iminens dalam dosis lebih dari $200 \mathrm{mg} / \mathrm{hari}$ konsentrasi progesteron sesuai dengan trimester pertama kehamilan. ${ }^{9}$
Kumulatif probabilitas kasus yang bertahan diamati setiap minggu sampai mencapai kehamilan 23 minggu pada kedua kelompok dan dianalisis menggunakan weekly life table. Ternyata hasil pada kedua kelompok tidak menunjukkan perbedaan bermakna. Probabilitas kasus yang bertahan secara kumulatif dari kelompok progesteron vaginal adalah 77\% sampai minggu kelima, sedangkan kelompok allylestrenol oral adalah $60 \%$ sampai minggu keempat (Gambar 1).

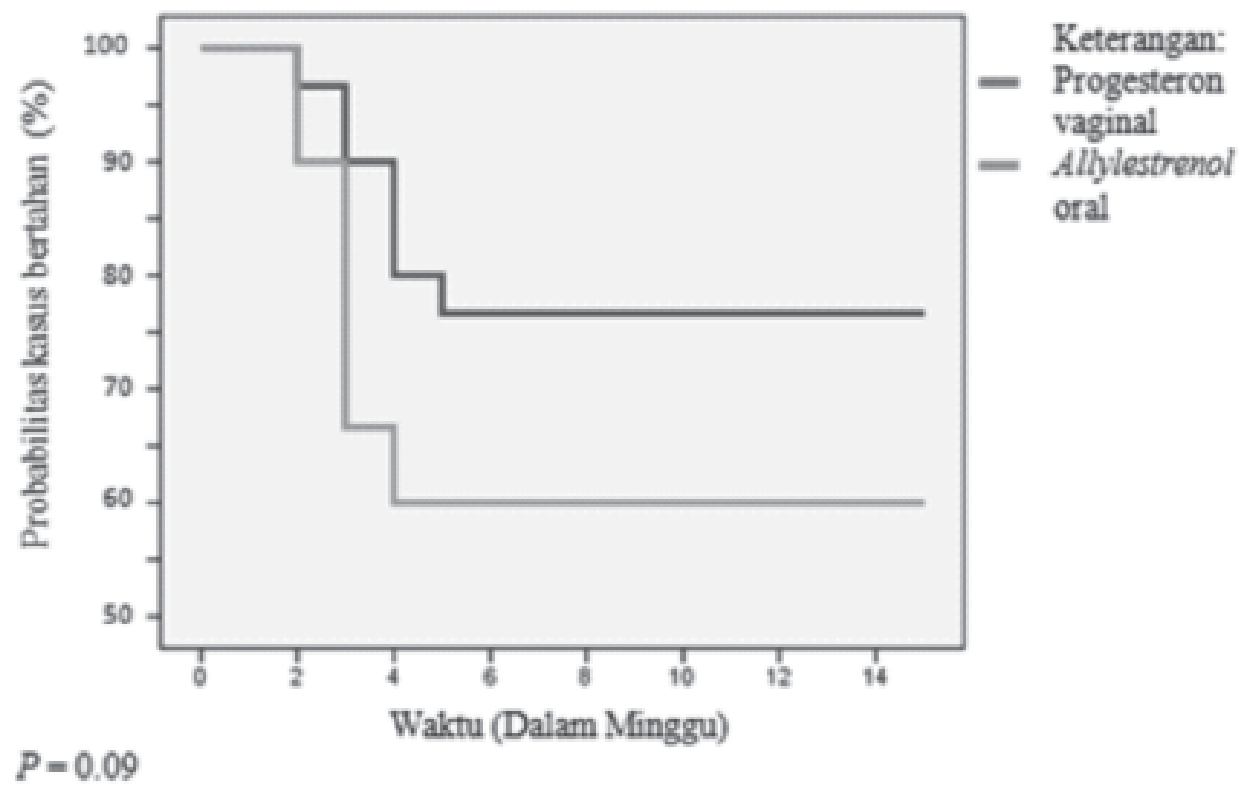

Gambar 1. Jumlah Kumulatif Probabilitas Kasus Yang Bertahan Tiap minggu (\%) Kedua Kelompok Penelitian 
Pemberian progesteron vaginal dan allylestrenol oral memiliki beberapa fungsi pada wanita hamil meliputi relaksasi otot polos miometrium, pemblokiran aksi oksitosin, dan penghambatan pembentukan gap junction sehingga dapat mempertahankan kehamilan. ${ }^{11}$ Dibanding allylestrenol oral, progesteron vaginal penyerapan berlangsung cepat, progesteron terakumulasi di dalam rahim, tingkat progesteron yang tinggi dalam plasma darah dalam satu jam setelah pemberian. ${ }^{9}$

Efek samping yang terjadi pada penelitian ini berupa keluhan gastrointestinal yaitu perasaan mual yang diderita pada 4 kasus pada kelompok allylestrenol oral dan tidak ada keluhan pada kelompok progesteron vaginal, dan tidak berbeda dengan penelitian sebelumnya. ${ }^{4}$ Pemberian secara oral sangat mudah diterima oleh pasien tetapi menunjukkan banyak kelemahan, antara lain variabilitas ekstrim dalam konsentrasi plasma oleh karena perbedaan variabilitas individu dalam hal pengisian lambung dan sirkulasi enterohepatik. Selain dari itu pemberian oral juga menghasilkan efek samping seperti mual, sakit kepala, mengantuk. Pemberian secara vaginal menghasilkan konsentrasi yang lebih tinggi di dalam uterus tetapi tidak mencapai tingkat yang tinggi dan konstan dalam darah. ${ }^{10}$

\section{KESIMPULAN DAN SARAN}

Penelitian ini menyimpulkan bahwa tidak ada perbedaan bermakna secara statistik dalam mempertahankan kehamilan pada kasus abortus iminens antara kelompok progesteron vaginal dibanding dengan allylestrenol oral. Progesteron vaginal cukup aman diberikan karena tidak mempunyai efek gastrointerstinal. Penelitian lebih lanjut dengan metode double blind perlu dilakukan untuk memperoleh hasil yang lebih dapat dipercaya.

\section{DAFTAR PUSTAKA}

1. World Health Organization. International Statistical Classification of Diseases and Related Health Problems. 10th Edition.Vol.1, Geneva: World Health Organization, 1992

2. Wahabi HA, Abed Althagafi NF, Elawad M. Progestogen for treating threatened miscarriage. Cochrane Data base of Systematic Reviews 2007, Issue 3. Art. No.:CD005943.DOI:10.1002/ 14651858.CD005943.pub2

3. Sagili H, Divers M. Modern management of miscarriage. The Obstetrician \& Gynaecologist, 9:102-108, 2007

4. Sugito B, Siswosudarmo R. Efektifitas Allylestrenol untuk pengobatan abortus iminens. Tesis PPDS OBSGIN. Fakultas Kedokteran Universitas Gadjah Mada. Yogyakarta,1990

5. Palagiano A, Bulletti C, Pace MC, De Ziegler D, Cicinelli E, Izzo A. Effects of vaginal progesterone on pain and uterine contractility in patients with threatened abortion before twelve weeks of pregnancy. Annals of theNew York Academy of Sciences, 1034:200-10, 2004

6. Mackenzie EW, Holmes SD, Newton RJ, Spontaneus abortion Rate In Ultrasonographically Viable Pregnancies. Obstet. Gynaecol. 71:81-3. 1988

7. Anwar R. Endokrinologi kehamilan dan persalinan. Bandung: FK Unpad; 2005

8. Cunningham FG, Leveno KJ, Bloom SL, Hauth JC, Rouse DJ, Spong CY. Abortion. Williams obstetrics. 23st Edition. New York: McGraw-Hill, pp.215-234, 2010

9. Golub MS, Kaufman FL, Campbell MA, Li LH. Evidenceon the developmental and reproductive toxicity of progesterone. 2004

10. Di Renzo GC, Rosati A, Mattei A, Gojnic M, GerliS. The changing role of progesterone in preterm labour. British Journal of Obstetrics and Gynaecology, Vol.112, Supplement 1, pp.57-60, 2005

11. Dastur AE, Progesterone and preterm delivery are we coming a full circle?.J Obstet Gynecol IndiaVol. 58, No. 4: July/August 2008. 